\title{
Differentiation and Transplantation of Human Embryonic Stem Cell-Derived Hepatocytes
}

\author{
Hesham Basma ${ }^{1}$, Alejandro Soto-Gutiérrez ${ }^{3}$, Govardhana Rao Yannam ${ }^{1}$, Liping Liu ${ }^{1}$, \\ Ryotaro Ito ${ }^{1}$, Toshiyuki Yamamoto ${ }^{1}$, Ewa Ellis ${ }^{4}$, Steven D. Carson ${ }^{2}$, Shintaro Sato ${ }^{3}$, Yong \\ Chen ${ }^{7}$, David Muirhead ${ }^{2}$, Nalu Navarro-Álvarez ${ }^{3}$, Ron Wong ${ }^{5}$, Jayanta Roy-Chowdhury ${ }^{8}$, \\ Jeffrey L. Platt ${ }^{6}$, David F. Mercer ${ }^{1}$, John D. Miller ${ }^{1}$, Stephen C. Strom ${ }^{4}$, Noaya Kobayashi ${ }^{3}$, \\ and Ira J. Fox ${ }^{1}$ \\ ${ }^{1}$ Department of Surgery, University of Nebraska Medical Center, Omaha, NE 68198, USA \\ ${ }^{2}$ Department of Pathology and Microbiology, University of Nebraska Medical Center, Omaha, NE \\ 68198, USA \\ ${ }^{3}$ Department of Surgery, Okayama University Graduate School of Medicine and Dentistry, 2-5-1 \\ Shikata-cho, Okayama, Japan \\ ${ }^{4}$ Department of Pathology, University of Pittsburgh School of Medicine, Pittsburgh PA 15261, USA \\ ${ }^{5}$ Department of Pediatrics, Stanford University School of Medicine, Stanford, CA 94305, USA \\ ${ }^{6}$ Departments of Surgery and Microbiology and Immunology, University of Michigan, Ann Arbor MI \\ 48109, USA \\ ${ }^{7}$ Department of Medicine (Hepatology Division) and Marion Bessin Liver Research Center, Albert \\ Einstein College of Medicine, NY 10461 USA \\ ${ }^{8}$ Departments of Medicine (Hepatology Division) and Genetics, and Marion Bessin Liver Research \\ Center, Albert Einstein College of Medicine, Bronx, NY 10461 USA
}

\begin{abstract}
Background \& Aims-The ability to obtain unlimited numbers of human hepatocytes would improve development of cell-based therapies for liver diseases, facilitate the study of liver biology and improve the early stages of drug discovery. Embryonic stem cells are pluripotent, can potentially differentiate into any cell type and could therefore be developed as a source of human hepatocytes.
\end{abstract}

\begin{abstract}
Methods-To generate human hepatocytes, human embryonic stem cells were differentiated by sequential culture in fibroblast growth factor 2 and human Activin-A, hepatocyte growth factor, and dexamethasone. Functional hepatocytes were isolated by sorting for surface asialoglycoprotein receptor expression. Characterization was performed by real-time PCR, imunohistochemistry, immunoblot, functional assays and transplantation.

Results-Embryonic stem cell-derived hepatocytes expressed liver-specific genes but not genes representing other lineages, secreted functional human liver-specific proteins similar to those of primary human hepatocytes and demonstrated human hepatocyte cytochrome P450 metabolic activity. Serum from rodents given injections of embryonic stem cell-derived hepatocytes contained significant amounts of human albumin and alpha-1-antitrypsin. Colonies of cytokeratin-18 and human albumin-expressing cells were present in the livers of recipient animals.
\end{abstract}

Correspondence should be addressed to (current address): Ira J Fox M.D, Department of Surgery, University of Pittsburgh, Pittsburgh, PA 15213, USA, Tel: 1-412-692-7133, Fax: 1-412-692-6599, foxi@upmc.edu.

Conflicts of interest: There are no conflicts of interest to disclose. 
Conclusion-Human embryonic stem cells can be differentiated into cells with many characteristics of primary human hepatocytes. Hepatocyte-like cells can be enriched and recovered based on asialoglycoprotein receptor expression and could potentially be used in drug discovery research and developed as therapeutics.

Transplantation of isolated hepatocytes has been shown in the laboratory and in patients to be a minimally invasive intervention that can augment the function of the liver ${ }^{1-3}$. This is an especially exciting alternative to organ transplantation for patients with acute decompensation of the liver or life threatening liver-based genetic disorders. A shortage of human livers, however, presently limits use of hepatocytes for transplantation. Thus, the availability of an unlimited supply of human hepatocytes would facilitate the development and clinical application of hepatocyte transplantation. An abundant source of human hepatocytes could also be used to repopulate the livers of immune deficient mice ${ }^{4}$, facilitating the study of human liver disease, hepatitis virus biology 5 , and human drug metabolism ${ }^{6,7}$.

Human hepatocyte-like cells have been generated from a variety of putative stem cell sources ${ }^{8-14}$. However, while investigators have generated cells with some characteristics approaching that of human hepatocytes, to date, no approach to generating hepatocytes from stem cells has succeeded in generating a homogeneous population of cells that could provide levels of function comparable to primary liver cells. Here we report a differentiation strategy that produces a relatively homogeneous population of cells from human embryonic stem (hES) cells that exhibit the morphologic and phenotypic properties of human hepatocytes.

\section{Materials and Methods}

\section{Differentiation program}

hES cells (H1) were obtained from WiCell Research Institute (Madison, WI) and maintained on mitotically inactive mouse embryo fibroblast feeder layers in Dulbecco's modified Eagle's medium/Ham's F-12 medium (DMEM/F12), high (20\%) Knockout Serum Replacement (KSR), $4 \mathrm{ng} / \mathrm{ml}$ human recombinant fibroblast growth factor-2 (FGF-2), $1 \mathrm{mM}$ nonessential amino acids, L-glutamine, $0.1 \mathrm{mM}$ 2-mercaptoethanol (Invitrogen, Carlsbad, CA). Embryonic bodies (EBs) were generated by plating collagenase passaged cells at a density of $1-5 \times 10^{4}$ cells per $\mathrm{cm}^{2}$ on low attachment Petri dishes for forty eight hours in DMEM/F12 supplemented with $15 \% \mathrm{KSR}, 1 \mathrm{mM}$ nonessential amino acids, L-glutamine. For differentiation, EBs were plated on 5\% Matrigel-Growth Factor Reduced (R\&D Systems Inc., Minneapolis), and maintained for three days in DMEM/F12 media supplemented with 100ng/ml Recombinant Activin A (R\&D Systems Inc., Minneapolis), 100ng/ml FGF-2 (Invitrogen, Carlsbad, CA). The concentration of serum (fetal bovine serum (FBS) or KSR) was $0 \%$ for the first 24 hours, $0.2 \%$ for the second 24 hours, and $2.0 \%$ for the last 24 hours. Cells were then grown for eight days in DMEM-F12 containing 10\% FBS or KSR, 1 mM nonessential amino acids, Lglutamine, $1 \%$ dimethyl sulfoxide (DMSO) (Sigma-Aldrich, St. Louis, MO) and 100ng/ml HGF (R\&D Systems Inc., Minneapolis), followed by culture for three additional days in DMEM-F12 containing 10\% FBS or KSR, $1 \mathrm{mM}$ nonessential amino acids, L-glutamine, $10^{-7} \mathrm{M}$ dexamethasone (Sigma-Aldrich, St. Louis, MO).

\section{Animals}

Male NOD/SCID mice, Alb-uPA SCID mice ${ }^{15}$, and Nagase analbuminemic rats ${ }^{16}$ were bred in the animal breeding facility at the University of Nebraska Medical Center, and were used for transplantation procedures. All procedures performed on animals were approved by the University of Nebraska Medical Center Animal Care and Use Committee, and thus within the guidelines for humane care of laboratory animals. 


\section{Transplantation}

One million hES cells, recovered after 18 days of differentiation, were transplanted into the spleens of NOD-SCID mice using a 25-gauge needle. Recipient NOD-SCID mice were injected on two occasions prior to transplantation with $70 \mathrm{mg} / \mathrm{kg}$ retrorsine, separated by two weeks, and underwent $50 \%$ partial hepatectomy four weeks later, at the time of transplantation ${ }^{17}$. Nagase rat recipients were similarly treated twice with $30 \mathrm{mg} / \mathrm{kg}$ of retrorsine separated over two weeks, and underwent a $70 \%$ partial hepatectomy just prior to transplantation ${ }^{18}$. Administration of FK506 at $2 \mathrm{mg} / \mathrm{kg} / \mathrm{d}$ in these animals controls rejection of xenogeneic hepatocytes for at least two months (unpublished data). Following transplantation of one million asialoglycoprotein receptor (ASGPR)-sorted differentiated hES cells into the spleen of a Nagase analbuminemic rat, human albumin levels were measured weekly by ELISA. Three week old Alb-uPA SCID mice underwent transplantation without treatment with retrorsine or partial hepatectomy by intrasplenic injection. Graft survival was assessed by serum measurements of human albumin and alpha-1-antitrypsin (AAT) levels, which were measured by ELISA.

\section{Polymerase chain reaction}

RNA was prepared using a Qiagen RNeasy Mini Kit. Chromosomal DNA was removed using RNase-free DNase (Qiagen, Hilden, Germany), and cDNA was prepared using the Superscript First Strand synthesis system (Invitrogen, Carlsbad, CA) using $1 \mu \mathrm{g}$ of total RNA. Specific primers used for RT-PCR are described in the Supplementary Table 1. PCR products were resolved on $1 \%$ agarose gels and visualized by ethidium bromide staining. Human glyceraldehyde-3-phosphate dehydrogenase (GAPDH) and cyclophilin served as internal controls. Real-time RT-PCR was performed as previously described ${ }^{19}$.

\section{Flow analysis and sorting of ASGPR-expressing ES-derived hepatocytes}

ES-derived cells were trypsinized and resuspended in DMEM-F12 supplemented with 10\% SR. Cells were allowed to recover for 30 minutes and then centrifuged at $1200 \mathrm{rpm}$. Nonspecific binding was blocked using $100 \mu 1$ Human FC for 30 minutes, and then cells were treated for 30 minutes with a $100 \mu \mathrm{l}$ solution containing a goat-anti-human ASGPR1 antibody diluted 1:50 (Santa Cruz Biotechnology Inc., CA). A FITC-labeled mouse anti-goat antibody was added to the cells for 30 minutes at concentration of $0.5 \mu \mathrm{g} / \mathrm{ml}$. Cells were washed three times with 1ml FACS buffer (1\% Sodium Azide, 2\% FBS in PBS), resuspended in $500 \mu 1$ FACS buffer, and sorted by flow cytometry. Cell sorting was performed on a Becton-Dickinson FACSVantage DiVa flow cytometer data acquisition and analysis was performed using Becton-Dickinson DiVa software (Becton-Dickinson, San Jose, CA).

\section{Electron Microscopy}

Cells were fixed in 2\% paraformaldehyde and 2.5\% glutaraldehyde in Millonig's phosphate buffer, $\mathrm{pH} 7.38$, post-fixed in buffered $1 \%$ osmium tetroxide, washed in triple distilled water, dehydrated in a graded ethyl alcohol series, infiltrated and embedded with Epon resin (Electron Microscopy Sciences, Fort Washington, PA) and polymerized at $60^{\circ} \mathrm{C}$ for 48 hours. Multiple $1 \mu \mathrm{m}$ sections were stained with $0.5 \%$ Toludine blue and $0.5 \%$ Borax, and evaluated by light microscopy. Representative areas were selected. Silver sections, $70 \mathrm{~nm}$, mounted on 300 mesh Athene copper grids, were stained with uranyl acetate followed by Reynold's lead citrate and examined with a JEOL 1230 transmission electron microscope at $60 \mathrm{kV}$. Representative digital images were taken using a SIS Keenview camera and software.

\section{Measurement of coagulation factor (CF) VII activity}

CF VII activity was measured by monitoring the release of p-nitroanilide from Spectrozyme FXa by factor Xa (fXa), generated from factor X by tissue factor-bound CF VII ${ }^{20}$. A Tmax 
plate reader (Molecular Devices) was used to monitor the assays conducted in 96-well plates (Falcon). Stocks of purified CF VIIa (Novo Nordisk) and fX (purified from human plasma

21 and homogenized human brain powder ${ }^{22}$ ) were diluted prior to use in Tris-buffered saline (0.05M Tris $0.1 \mathrm{M} \mathrm{NaCl}, \mathrm{pH} 7.6$ ) containing $1 \mathrm{mg} / \mathrm{mL}$ bovine serum albumin (Sigma). For measurement of CF VII, 20uL of spent medium was combined with $10 \mathrm{uL}$ of the Tris buffer with BSA, $50 \mathrm{uL}$ of $1 / 100$ dilution of brain homogenate, $20 \mathrm{uL} \mathrm{fX}$ (concentration in the final $160 \mathrm{uL}$ assay volume was approximately $100 \mathrm{nM}$ ), $50 \mathrm{uL} 25 \mathrm{mM}$ calcium chloride, and $10 \mathrm{uL}$ of Spectrozyme FXa (final concentration 310uM). A CF VIIa calibration curve was generated concurrently using serial dilutions of the pure CF VIIa in place of the spent medium. The plot of $\mathrm{fXa}[\mathrm{pM}] / \mathrm{min}$ versus CF VIIa $[\mathrm{pM}]$ was described by $\mathrm{y}=\left(1141\left(\mathrm{x}^{0.73}\right)\right) /\left(\left(\mathrm{x}^{0.73}\right)+45.8\right)-0.44$ in the second assay, for which the CF VIIa dilutions covered the range of activities measured with the spent medium.

\section{Metabolic activity}

ES-derived- or normal human hepatocytes were plated in HMM (Lonza) media at a density of 1.5 million cells per well in collagen-coated 6 well plates. Cells were cultured for 72 hours in the presence of $1 \mathrm{mM}$ Phenobarbital or $25 \mu \mathrm{M}$ beta-naphthoflavone (BNF) as previously described ${ }^{23,24}$. Following the induction period, cells were washed three times to remove inducers, and media was replaced with fresh media (without inducers). For the measurement of cytochrome P450 (CYP) 1A activity, cells we exposed to media containing $20 \mu \mathrm{M} 7$ ethoxyresorufin and $1.5 \mathrm{mM}$ salicylamide for one hour. The conversion of 7-ethoxy to 7hydroxyresorufin in the media was quantified by the fluorescence of the 7-hydroxy metabolite measured at $535 \mathrm{~nm}(\mathrm{Ex})$ and $581 \mathrm{~nm}(\mathrm{Em})^{24}$. Salicylamide is used to prevent the conjugation of resorufin formed by de-ethylation. The analysis of CYP3A activity was measured by exposing cells to $350 \mu \mathrm{M}$ testosterone for one hour. The conversion of testosterone to $6 \beta$ hydroxytestosterone was measured by a high pressure liquid chromatographic method as previously described ${ }^{23}$.

\section{Results}

\section{Differentiation of hES toward a hepatocyte phenotype}

To generate ES cell-derived hepatocytes, human (H1) ES cells were plated on low attachment Petri dishes to form embryoid bodies. EBs were then plated on $5 \%$ Matrigel for three days in recombinant Activin A and FGF-2. Cells were then grown for eight days in 10\% serum (or KSR) containing HGF, followed by culture for three additional days in $10 \%$ serum or KSR, and $10^{-7} \mathrm{M}$ dexamethasone (Figure 1A and Supplementary Figure 1).

Real time and RT-PCR analysis was performed on cell preparations at various times during the culture process to determine the time course and degree to which the ES cells differentiated toward a hepatocyte phenotype. Analysis included markers for endoderm-specific gene expression (sox 17 and AFP), hepatocyte-specific gene expression, [albumin, ASGPR 1, and or CF VII], and markers for undifferentiated hES cells (Pou5f1 and Nanog). As shown in Figures 1B and 1C, endoderm-specific gene expression increased early while Pou5f1 and Nanog expression gradually decreased and hepatocyte-specific gene expression progressively increased over the course of the differentiation program.

To determine the percentage of cells differentiating toward a hepatic phenotype, immunohistochemistry was performed for albumin and AFP. As shown in Figure 1D, undifferentiated H1 hES cells had large nuclei, as demonstrated by DAPI staining, and expressed some AFP, probably representing low-grade spontaneous differentiation in culture, but no albumin. Following culture in growth factors, approximately 55\% of cells expressed albumin, only $12 \%$ of which co-expressed AFP. There was also a dramatic change in 
morphology during the course of the differentiation process. As shown in Figure 2, polygonal shaped cells containing multiple nuclei formed and transmission electron microscopy revealed cells containing glycogen granules (Figure 2B), mature round nuclei with evenly distributed chromatin, and Golgi complexes (Figure 2C), and well developed bile canaliculi with apical microvilli and tight junctions (Figures 2D, 2E).

Transplant studies were then performed to determine whether differentiated hES cells would, like primary hepatocytes, home to and engraft in the liver after injection in the spleen. To allow non-invasive tracking of cells after transplantation, differentiated hES cells were transduced with a recombinant lentivirus containing the gene encoding firefly luciferase under the control of the human albumin promoter ${ }^{25}$. One million cells were transplanted into the spleens of immune deficient NOD-SCID mice. Prior to transplantation, recipient mice were injected twice with $70 \mathrm{mg} / \mathrm{kg}$ retrorsine, and underwent a $50 \%$ partial hepatectomy at the time of transplantation (Figure 3A). Under these conditions, the transplanted cells have a selective growth advantage compared to the native liver cells, whose proliferation is blocked by retrorsine 17,18 . After transplantation, the serum of NOD-SCID mouse recipients of differentiated hES contained 500-1000 ng/ml human albumin and 100-200 ng/ml human AAT (Figure 3B). Control mice transplanted with primary porcine hepatocytes contained approximately $500 \mathrm{ng} / \mathrm{ml}$ porcine albumin (Figure 3B). As shown in Figure 3C whole mouse IVIS ${ }^{\mathrm{TM}}$ imaging performed 21 days after transplantation revealed that differentiated cells containing an active albumin promoter, and thus expressing luciferase, had traveled through the portal circulation after introduction into the spleen to engraft in the livers of transplanted mice. No luciferase-expressing ES-derived cells appeared in the location of the spleen. At sacrifice on post-transplant day 21, however, gross and histologic examination revealed teratomas in the liver, spleen and peritoneal cavity containing poorly differentiated cells.

\section{Enrichment for hES-derived hepatocytes based on ASGPR expression}

To isolate the population of cells with a differentiated hepatocyte phenotype and reduce or eliminate the undifferentiated or poorly differentiated cells, or cells that might have differentiated toward a different cell lineage, differentiated hES cells were sorted by flow cytometry for expression of the ASGPR, a definitive feature of hepatocytes. As shown in Figure 4A approximately 18-26\% of hES-derived cells expressed ASGPR. Nucleic acids from the sorted population, from undifferentiated $\mathrm{hES}$ cells, and from $\mathrm{hES}$ cells during the various stages of the differentiation process were then assessed by RT-PCR and real time analysis to determine the extent to which enrichment toward a hepatocyte phenotype resulted from sorting (Figures 4B, 4C). Real time PCR showed that the sorted cells had a gene expression profile near that of primary adult human hepatocytes. Cells also expressed the genes encoding bilirubin-UDP glururonosyl transferase, ornithine transcarbamylase, and the bile salt export pump (Supplementary Figure 2A). RT-PCR performed for Pdx-1 (a pancreatic marker gene), Nestin (ectoderm), Brachury (mesendoderm), NKx2.5 (mesoderm), and Pax-6 (ectoderm) demonstrated that the sorting process dramatically enriched for cells that did not express genes representing other lineages (Figure 4D). Complete loss of Pou5f1 and Nanog indicated elimination of less differentiated cells, and loss of Sox 17 indicated enrichment of cells beyond the endoderm stage of development. A small amount of AFP expression remained present in sorted cells, indicating the presence of cells that could represent late gestation fetal hepatocytes.

\section{Characterization and transplantation of ASGPR-enriched ES-derived cells}

To determine the capacity of differentiated hES to function as primary hepatocytes we examined production of CF VII, a gene product specific to hepatocytes. Western blot (Figure 4E) and functional assay of Vitamin K supplemented cell supernatants from sorted ES-derived "hepatocytes" showed production of functionally active CF VII on the order of that produced by primary human hepatocytes cultured under the same conditions (Figure 4F). Cells were also 
assessed for their ability to generate human albumin, AAT, and urea in culture. Cells enriched by sorting for ASGPR expression generated approximately $75 \%$ of the albumin, $65 \%$ of the AAT, and $65 \%$ of the urea generated by primary human hepatocytes (Figure 5A). ES-derived cells were also assessed for expression of human hepatocyte-specific cytochrome P450 metabolizing genes and P450 metabolic activity. ASGPR-sorted differentiated hES cells expressed CYP 1A1, 1A2, 2B6, 3A4, and 7A1 by real-time PCR (Figure 5B), converted testosterone to 6-beta-hydroxytestosterone, a specific measure of CYP 3A4-mediated metabolism, and demonstrated inducible hepatic CYP 1A1/1A2-mediated Ethoxyresorufin-Odeethylase (EROD) activity (Figure 5C).

One hundred thousand to 200,000 ASGPR-sorted differentiated cells were then transplanted into each of five Alb-uPA SCID mice. The Alb-uPA SCID mouse is a T- and B-cell deficient mouse that carries a tandem array of murine urokinase genes under the control of an albumin promoter ${ }^{15,26}$. The transgene is toxic to the host liver, and prevents native hepatocytes from responding with regeneration. At 75 days after transplantation, the serum of these animals contained 1000-2000 ng/ml human albumin and AAT (Figure 6A). Serum albumin levels from control animals transplanted with one million primary human hepatocytes derived from fresh liver resection specimens (Supplementary Table 2) or cadaver donor livers not used for transplantation range from less than $1000 \mathrm{ng} / \mathrm{ml}$ to greater than $1 \mathrm{mg} / \mathrm{ml}$ depending on donor age and source ${ }^{27}$. At sacrifice, examination of liver specimens from transplanted animals revealed small human cytokeratin-18 staining clusters of engrafted cells throughout the liver (Figure 6B). No teratomas or tumors were identified in these animals by gross or histologic examination. One million sorted cells were also transplanted into the spleen of one FK506immune suppressed Nagase analbuminemic rat. Prior to transplantation, the recipient animal was injected with retrorsine and underwent a 70\% partial hepatectomy at the time of transplantation, similar to what had been done previously in NOD SCID mice, to create an environment where there was a selective growth advantage to the transplanted cells. At 28 days after transplantation the blood of this recipient contained $2000 \mathrm{ng} / \mathrm{ml}(0.002 \mathrm{mg} / \mathrm{ml})$ human albumin. For comparison, 28 days after transplantation with 5 million primary pig hepatocytes, serum porcine albumin levels of approximately $5000 \mathrm{ng} / \mathrm{ml}(0.005 \mathrm{mg} / \mathrm{ml})$ were obtained (Figure 6C). At 55 days after transplantation the blood of the animal that received ASGPRsorted differentiated cells contained 20,000 ng/ml $(0.02 \mathrm{mg} / \mathrm{ml})$ human albumin (Figure 6C). Examination of liver specimens from this animal revealed large human albumin staining clusters of engrafted cells present throughout the liver (Figure 6D). Thus, ES-derived human hepatocytes were capable of homing to and engrafting normally in the liver, expanding in response to a physiologic proliferation signal, and secreting functional liver-specific proteins after engraftment. Unfortunately, while there were no intrahepatic tumors, the peritoneum contained tumors histologically consistent with well differentiated adenocarcinoma (Supplementary Figure 2B).

\section{Discussion}

In these studies, we present a simple and reproducible method for generating functional human hepatocytes from pluripotent ES cells. Although successful methods for hepatic differentiation of hES cells have been described, none have generated cells with function adequate for clinical use ${ }^{8,12,28-30}$. We have not determined whether co-culture with liver non-parenchymal cells might increase the efficiency of hepatic differentiation, as has been described for mouse ES cell differentiation ${ }^{31}$. Hepatic differentiation, greater than the $18-26 \%$ described here, would be desirable, but the simplicity of the protocol may facilitate clinical application and the eventual scaling up that will be required to generate ES-derived hepatocytes in numbers that could be used in patients. 
The protocol we describe incorporates a step involving generating EBs. However, based on the work of D'Amour et al ${ }^{32}$, we have performed a number of additional real-time PCR and albumin and urea production experiments that show essentially identical hepatocyte-specific differentiation whether or not the EB formation step is included in the differentiation program. In fact, there is more extensive and earlier loss of Oct 3/4, Nanog, Sox 7, and AFP when the EB step is removed (Supplementary Figure 3). In addition, our ability to induce differentiation using KSR instead of serum allows removal of animal products from the process, an important consideration for clinical application.

A critically important component of the differentiation protocol relates to enrichment for ESderived hepatocytes. ASGPR expression is unique for liver cells ${ }^{33}$. While $55 \%$ of differentiated cells expressed albumin by immunohistochemistry, significantly fewer cells expressed ASGPR, indicating that enrichment based on ASGPR expression may be more selective than sorting based on previously-described gene transfer techniques using reporter genes driven from liver-specific promoters. The present strategy does not depend on transduction efficiency for selecting a relatively homogeneous population of cells. While we employed flow sorting for enrichment, this technique is relatively time consuming and can lead to significant cell injury. In addition, its efficacy can be affected by sorting speed, which can seriously affect the yield and viability of the differentiated ES cells recovered and allow recovery of unwanted cells. The ASGPR-based sorting approach outlined, however, would also be amenable to enrichment by magnetic sorting ${ }^{34}$ or panning on antibody coated plates. Such strategies might be more efficient than flow sorting since the steps can be performed repeatedly for enhanced selection, and would result in significantly less damage to the recovered cells. In addition, they might be faster and more appropriate for large scale high-throughput enrichment than flow cytometry.

As demonstrated in our studies, tumor risk remains an issue that must continue to be addressed. It appears that neither the number of cells that can be transplanted into immune deficient mice nor the length of time transplanted rodents can be followed will be adequate to unequivocally determine whether cell preparations are safe for clinical use. Large scale studies, performed in non human primates using frozen stocks of differentiated cells, when possible, may be needed for such an analysis. While ES cell-derived hepatocytes may not be immediately useful for transplantation therapies, they are likely to find early application for the study of human drug metabolism and drug discovery. Mature human livers express important drug metabolizing enzymes ${ }^{35}$, some of which are inducible following exposure to phenobarbital or (BNF) 23 , ${ }^{24}$. Our studies indicate that ES-derived hepatocytes express human CYP genes at levels near those of adult human hepatocytes, and that prior exposure to BNF results in robust induction in the metabolism of ethoxyresorufin, a known substrate for CYP 1A1/2, by both ES-derived hepatocytes and normal human liver cells. Our studies also show that ES-derived hepatocytes and normal human hepatocytes convert testosterone to 6-beta-hydroxytestosterone, a specific measure of CYP 3A4-mediated metabolism, to a similar degree in culture. While prior exposure to phenobarbital did not increase the metabolism of testosterone in ES-derived cells, as occurs with normal human hepatocytes (data not shown), the CYP metabolic activity demonstrated by ES-derived cells is substantial. It is possible that further maturation of CYP functional activity may require differentiation on a more physiologic extracellular matrix or interaction with other cells.

While we have examined the use of hES cells in this series of experiments, successful generation of hepatocytes from precursors derived from individual patients ${ }^{36}$ could lead to the development of individualized patient-specific drug regimens and might eventually be employed to circumvent the need for life-long immune suppression following hepatocyte transplantation. In summary, these studies provide a foundation for efficient development of functional human hepatocytes from hES cells. Further studies will be needed to determine 
whether the differentiation protocol and enrichment strategy outlined can be scaled for use in patients and can be modified to eliminate the risk of contaminating cells and risk of tumor formation following transplantation. Application of ES-derived hepatocytes for the study of human drug metabolism and drug discovery, however, may soon be possible.

\section{Supplementary Material}

Refer to Web version on PubMed Central for supplementary material.

\section{Acknowledgments}

We thank Melissa Holzapfel for careful preparation of samples for electron microscopy.

Supported by a Grant-in-Aid for Scientific Research (B) of the Japan Society for the Promotion of Science (to N.K.), NIH grants DK-7-0004 (to S.C.S), HL52297 (to J.L.P.), DK 067440 (to J.R.C.), and DK48794 and AI49472 (to I.J.F.).

\section{Abbreviations used in this paper}

AAT, alpha-1-antitrypsin

AFP, alpha fetoprotein

ASGPR, asialoglycoprotein receptor

BNF, beta-naphthoflavone

CF VII, coagulation factor VII

CYP, cytochrome P450

DMEM/F12, Dulbecco's modified Eagle's medium F-12

DMSO, dimethyl sulfoxide

EB, embryoid bodies

EROD, ethoxyresorufin-O-deethylase

ES, embryonic stem

FBS, fetal bovine serum

FGF-2, fibroblast growth factor 2

fXa, factor Xa

GAPDH, glyceraldehyde-3-phosphate dehydrogenase

hES, human embryonic stem

KSR, Knockout Serum Replacement

\section{References}

1. Matas AJ, Sutherland DE, Steffes MW, Mauer SM, Sowe A, Simmons RL, Najarian JS. Hepatocellular transplantation for metabolic deficiencies: decrease of plasms bilirubin in Gunn rats. Science 1976;192:892-894. [PubMed: 818706]

2. Groth CG, Arborgh B, Bjorken C, Sundberg B, Lundgren G. Correction of hyperbilirubinemia in the glucuronyltransferase-deficient rat by intraportal hepatocyte transplantation. Transplant Proc 1977;9:313-316. [PubMed: 405772]

3. Fox IJ, Roy-Chowdhury J. Hepatocyte transplantation. J Hepatol 2004;40:878-886. [PubMed: 15158325]

4. Azuma H, Paulk N, Ranade A, Dorrell C, Al-Dhalimy M, Ellis E, Strom S, Kay MA, Finegold M, Grompe M. Robust expansion of human hepatocytes in Fah-/-/Rag2-/-/I12rg-/- mice. Nat Biotechnol 2007;25:903-910. [PubMed: 17664939]

5. Mercer DF, Schiller DE, Elliott JF, Douglas DN, Hao C, Rinfret A, Addison WR, Fischer KP, Churchill TA, Lakey JR, Tyrrell DL, Kneteman NM. Hepatitis C virus replication in mice with chimeric human livers. Nat Med 2001;7:927-933. [PubMed: 11479625]

6. Pouton CW, Haynes JM. Embryonic stem cells as a source of models for drug discovery. Nat Rev Drug Discov 2007;6:605-616. [PubMed: 17667955] 
7. Khetani SR, Bhatia SN. Microscale culture of human liver cells for drug development. Nat Biotechnol 2008;26:120-126. [PubMed: 18026090]

8. Lavon N, Yanuka O, Benvenisty N. Differentiation and isolation of hepatic-like cells from human embryonic stem cells. Differentiation 2004;72:230-238. [PubMed: 15270779]

9. Ruhnke M, Ungefroren H, Nussler A, Martin F, Brulport M, Schormann W, Hengstler JG, Klapper W, Ulrichs K, Hutchinson JA, Soria B, Parwaresch RM, Heeckt P, Kremer B, Fandrich F. Differentiation of in vitro-modified human peripheral blood monocytes into hepatocyte-like and pancreatic islet-like cells. Gastroenterology 2005;128:1774-1786. [PubMed: 15940611]

10. Hay DC, Fletcher J, Payne C, Terrace JD, Gallagher RC, Snoeys J, Black JR, Wojtacha D, Samuel K, Hannoun Z, Pryde A, Fillippi C, Currie IS, Forbes SJ, Ross JA, Newsome PN, Iredale JP. Highly efficient differentiation of HESCs to functional hepatic endoderm requires ActivinA and Wnt3a signaling. Proc Natl Acad Sci U S A 2008;105:12301-12306. [PubMed: 18719101]

11. Campard D, Lysy PA, Najimi M, Sokal EM. Native umbilical cord matrix stem cells express hepatic markers and differentiate into hepatocyte-like cells. Gastroenterology 2008;134:833-848. [PubMed: 18243183]

12. Cai J, Zhao Y, Liu Y, Ye F, Song Z, Qin H, Meng S, Chen Y, Zhou R, Song X, Guo Y, Ding M, Deng H. Directed differentiation of human embryonic stem cells into functional hepatic cells. Hepatology 2007;45:1229-1239. [PubMed: 17464996]

13. Miki T, Lehmann T, Cai H, Stolz DB, Strom SC. Stem cell characteristics of amniotic epithelial cells. Stem Cells 2005;23:1549-1559. [PubMed: 16081662]

14. Khurana S, Mukhopadhyay A. In vitro transdifferentiation of adult hematopoietic stem cells: An alternative source of engraftable hepatocytes. J Hepatol. 2008in press

15. Rhim JA, Sandgren EP, Palmiter RD, Brinster RL. Complete reconstitution of mouse liver with xenogeneic hepatocytes. Proc Natl Acad Sci U S A 1995;92:4942-4946. [PubMed: 7761429]

16. Nagase S, Shimamune K, Shumiya S. Albumin-deficient rat mutant. Science 1979;205:590-591. [PubMed: 451621]

17. Guo D, Fu T, Nelson JA, Superina RA, Soriano HE. Liver repopulation after cell transplantation in mice treated with retrorsine and carbon tetrachloride. Transplantation 2002;73:1818-1824. [PubMed: 12085007]

18. Laconi E, Oren R, Mukhopadhyay DK, Hurston E, Laconi S, Pani P, Dabeva MD, Shafritz DA. Longterm, near-total liver replacement by transplantation of isolated hepatocytes in rats treated with retrorsine. Am J Pathol 1998;153:319-329. [PubMed: 9665494]

19. Overbergh L, Giulietti A, Valckx D, Decallonne R, Bouillon R, Mathieu C. The use of real-time reverse transcriptase PCR for the quantification of cytokine gene expression. J Biomol Tech 2003;14:33-43. [PubMed: 12901609]

20. Carson SD. Manifestation of cryptic fibroblast tissue factor occurs at detergent concentrations which dissolve the plasma membrane. Blood Coagul Fibrinolysis 1996;7:303-313. [PubMed: 8735137]

21. Broze GJ Jr, Majerus PW. Purification and properties of human coagulation factor VII. J Biol Chem 1980;255:1242-1247. [PubMed: 7354023]

22. Pitlick FA, Nemerson Y. Purification and characterization of tissue factor apoprotein. Methods Enzymol 1976;45:37-48. [PubMed: 1012004]

23. Kostrubsky VE, Ramachandran V, Venkataramanan R, Dorko K, Esplen JE, Zhang S, Sinclair JF, Wrighton SA, Strom SC. The use of human hepatocyte cultures to study the induction of cytochrome P-450. Drug Metab Dispos 1999;27:887-894. [PubMed: 10421615]

24. Wen YH, Sahi J, Urda E, Kulkarni S, Rose K, Zheng X, Sinclair JF, Cai H, Strom SC, Kostrubsky VE. Effects of bergamottin on human and monkey drug-metabolizing enzymes in primary cultured hepatocytes. Drug Metab Dispos 2002;30:977-984. [PubMed: 12167562]

25. Lu Y, Dang H, Middleton B, Zhang Z, Washburn L, Campbell-Thompson M, Atkinson MA, Gambhir SS, Tian J, Kaufman DL. Bioluminescent monitoring of islet graft survival after transplantation. Mol Ther 2004;9:428-435. [PubMed: 15006610]

26. Meuleman P, Libbrecht L, De Vos R, de Hemptinne B, Gevaert K, Vandekerckhove J, Roskams T, Leroux-Roels G. Morphological and biochemical characterization of a human liver in a uPA-SCID mouse chimera. Hepatology 2005;41:847-856. [PubMed: 15791625] 
27. Utoh R, Tateno C, Yamasaki C, Hiraga N, Kataoka M, Shimada T, Chayama K, Yoshizato K. Susceptibility of chimeric mice with livers repopulated by serially subcultured human hepatocytes to hepatitis B virus. Hepatology 2008;47:435-446. [PubMed: 18098326]

28. Schwartz RE, Linehan JL, Painschab MS, Hu WS, Verfaillie CM, Kaufman DS. Defined conditions for development of functional hepatic cells from human embryonic stem cells. Stem Cells Dev 2005;14:643-655. [PubMed: 16433619]

29. Ek M, Soderdahl T, Kuppers-Munther B, Edsbagge J, Andersson TB, Bjorquist P, Cotgreave I, Jernstrom B, Ingelman-Sundberg M, Johansson I. Expression of drug metabolizing enzymes in hepatocyte-like cells derived from human embryonic stem cells. Biochem Pharmacol 2007;74:496503. [PubMed: 17568565]

30. Heo J, Factor VM, Uren T, Takahama Y, Lee JS, Major M, Feinstone SM, Thorgeirsson SS. Hepatic precursors derived from murine embryonic stem cells contribute to regeneration of injured liver. Hepatology 2006;44:1478-1486. [PubMed: 17133486]

31. Soto-Gutierrez A, Kobayashi N, Rivas-Carrillo JD, Navarro-Alvarez N, Zhao D, Okitsu T, Noguchi H, Basma H, Tabata Y, Chen Y, Tanaka K, Narushima M, Miki A, Ueda T, Jun HS, Yoon JW, Lebkowski J, Tanaka N, Fox IJ. Reversal of mouse hepatic failure using an implanted liver-assist device containing ES cell-derived hepatocytes. Nat Biotechnol 2006;24:1412-1419. [PubMed: 17086173]

32. D'Amour KA, Bang AG, Eliazer S, Kelly OG, Agulnick AD, Smart NG, Moorman MA, Kroon E, Carpenter MK, Baetge EE. Production of pancreatic hormone-expressing endocrine cells from human embryonic stem cells. Nat Biotechnol 2006;24:1392-1401. [PubMed: 17053790]

33. Stockert RJ. The asialoglycoprotein receptor: relationships between structure, function, and expression. Physiol Rev 1995;75:591-609. [PubMed: 7624395]

34. Handgretinger R, Lang P, Ihm K, Schumm M, Geiselhart A, Koscielniak E, Hero B, Klingebiel T, Niethammer D. Isolation and transplantation of highly purified autologous peripheral CD34(+) progenitor cells: purging efficacy, hematopoietic reconstitution and long-term outcome in children with high-risk neuroblastoma. Bone Marrow Transplant 2002;29:731-736. [PubMed: 12040469]

35. Strom SC, Pisarov LA, Dorko K, Thompson MT, Schuetz JD, Schuetz EG. Use of human hepatocytes to study P450 gene induction. Methods Enzymol 1996;272:388-401. [PubMed: 8791798]

36. Takahashi K, Tanabe K, Ohnuki M, Narita M, Ichisaka T, Tomoda K, Yamanaka S. Induction of pluripotent stem cells from adult human fibroblasts by defined factors. Cell 2007;131:861-872. [PubMed: 18035408] 
A
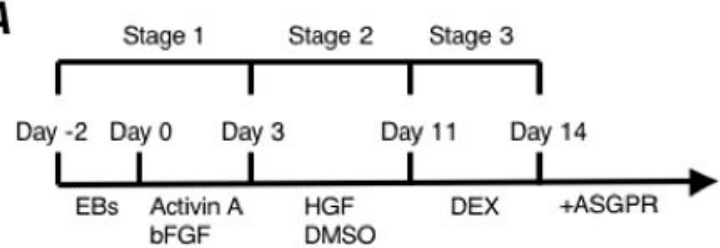

B
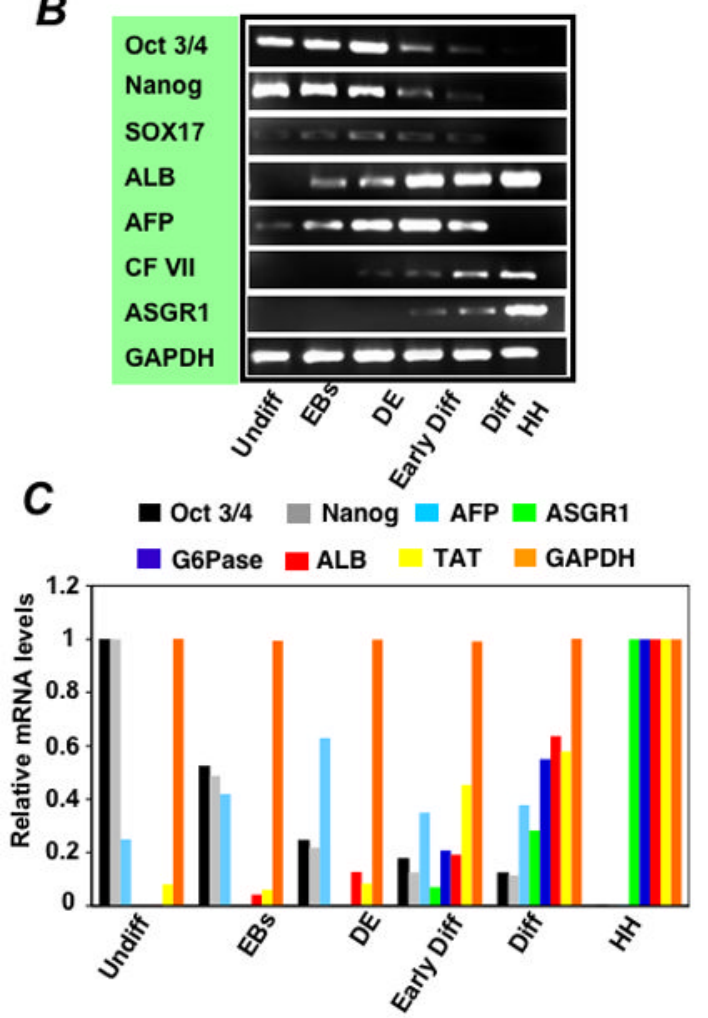

D
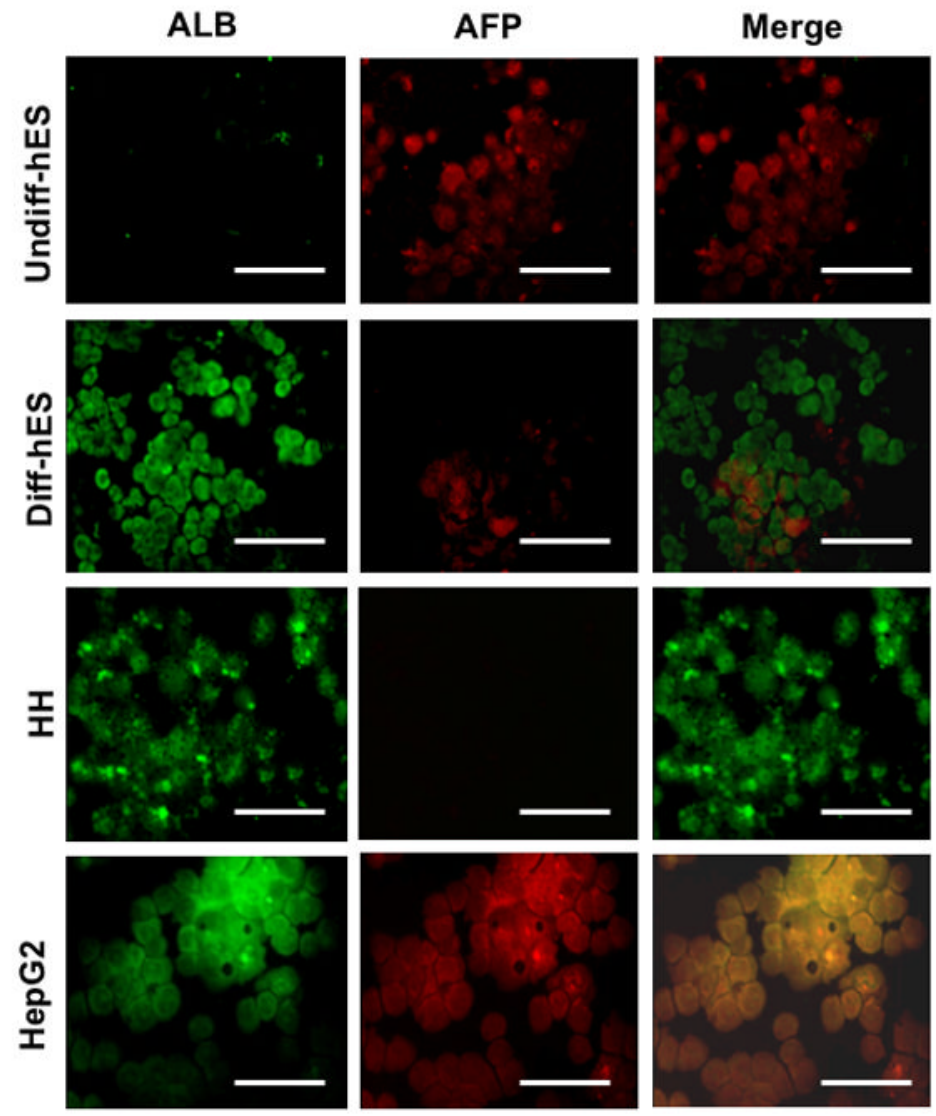

Figure 1. Differentiation of hES cells towards an hepatocytes phenotype and characterization of hepatocyte-directed cells

(A) Schematic representation of the strategy for differentiation of hES cells to hepatocytes.

(B) RT-PCR and (C) real time analysis for expression of lineage-specific hepatic markers [albumin (ALB), ASGPR 1, glucose-6-phosphatase (G6Pase), tyrosine aminotransferase (TAT), and CF VII], endoderm markers (SOX 17 and AFP), and markers for undifferentiated cells (Pou5f1 and Nanog). Lanes: (1) Undifferentiated hES cells (Undiff), (2) following EB formation (EBs), (3) following treatment with FGF-2 and Activin-A or at the definitive endoderm (DE) stage, (4) following culture in HGF and DMSO (Early Diff), (5) and after culture in dexamethasone (Diff-ES). Primary human hepatocytes served as the positive control. Forward and reverse primers used for these studies are listed in the Supplementary Table 2. Immunohistochemistry of hES cells at day 18 of the differentiation protocol, after final exposure to dexamethasone, for albumin, AFP, and merged albumin and AFP expression (D). Undifferentiated hES (Undiff hES), primary human hepatocytes (HH), and HepG2 cells were used as controls. Scale bar $50 \mu \mathrm{m}$. Approximately $55 \%$ of cells expressed albumin while only $12 \%$ co-expressed AFP. 

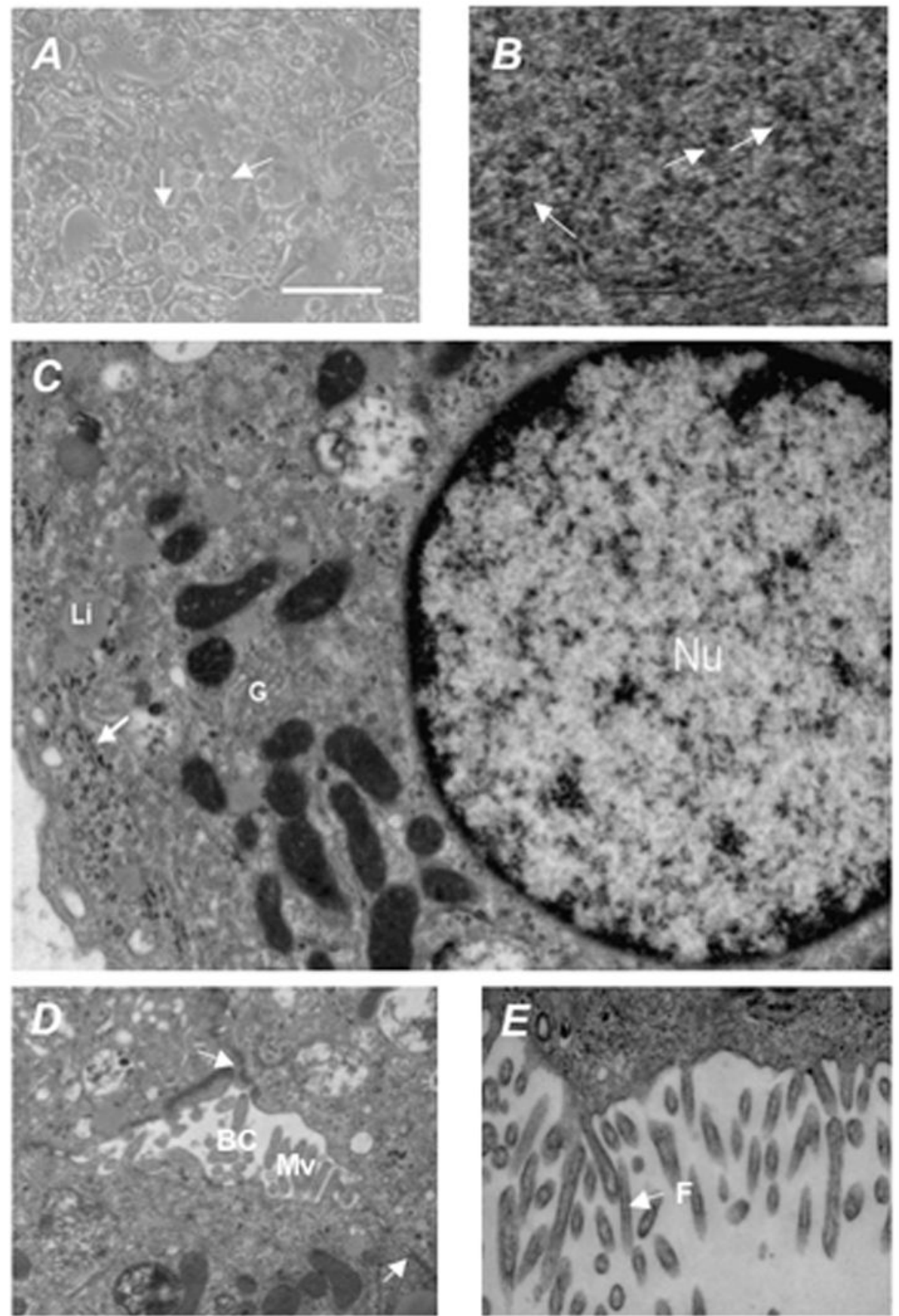

Figure 2. Morphological analysis of differentiated hES cells

Morphological analysis of differentiated hES cells in culture indicate that the differentiation program generated cells morphologically similar to hepatocytes, being polygonal in shape with multiple nuclei. (A) Transmission electron microscopy of differentiated hES showed (B) accumulation of glycogen rosettes (arrows), (C) round nuclei $(\mathrm{Nu})$ with evenly distributed chromatin, Golgi complexes (G), and liposomes (Li), with glycogen rosettes identified again by an arrow, and (D, E) well developed bile canaliculi (BC) with apical microvilli (Mv) containing filaments $(\mathrm{F})$, tight junctions (arrows). Scale bar $=50 \mu \mathrm{m}$. Original magnification $\times 30,000$. 
$\boldsymbol{A}$

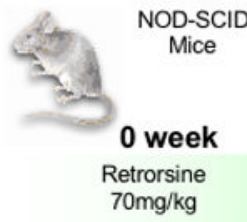

Intrasplenic transplantation of $1 \times 10^{6}$ hepatocytedifferentiated hES cells

2 week

Retrorsine $70 \mathrm{mg} / \mathrm{kg}$

B
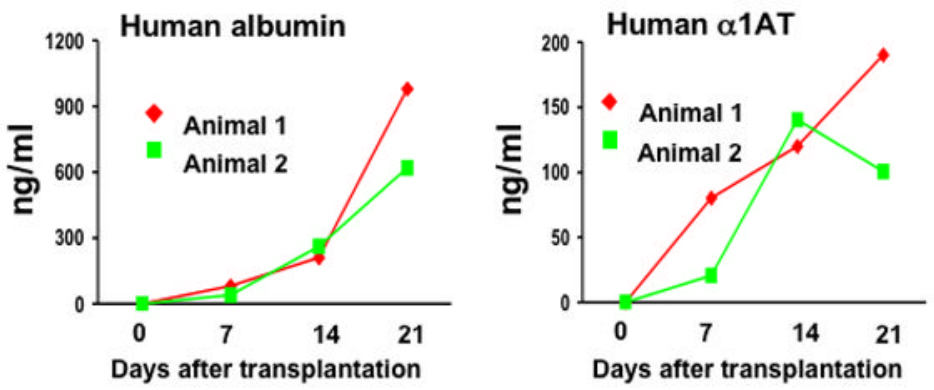

C

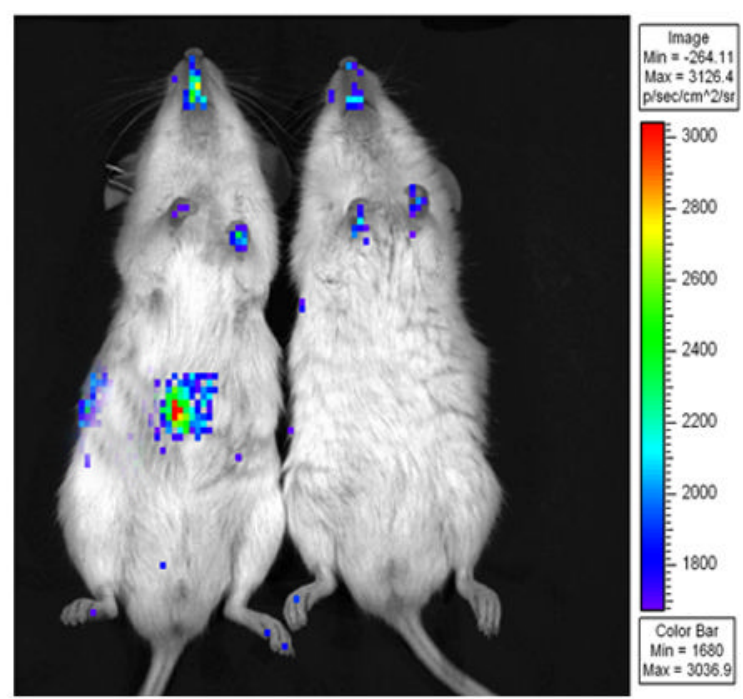

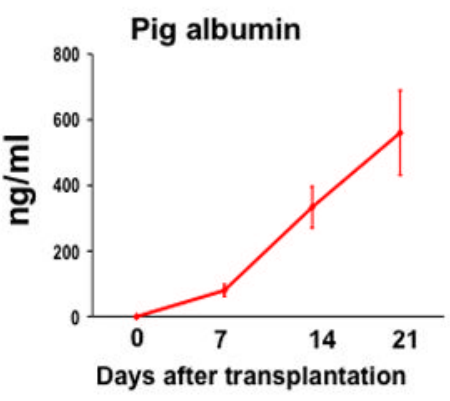

Figure 3. Transplantation of differentiated cells and characterization of cells sorted for surface ASGPR expression

(A) One million hepatocyte-differentiated hES cells were transplanted into retrorsine-treated immune deficient NOD-SCID mice following 50\% partial hepatectomy. Following transplantation, (B) human albumin and human $\alpha$ 1AT levels were measured by ELISA. Pig albumin levels in control mice transplanted with primary porcine hepatocytes are shown for comparison. (C) Imaging for luciferase expressing cells was performed three weeks after transplantation. Prior to transplantation, differentiated hES cells were transduced to express firefly luciferase. Differentiated cells containing an active albumin promoter, and thus expressing luciferase, appear to have traveled through the portal circulation after introduction into the spleen to engraft in the livers of transplanted mice. There was no evidence of luciferaseexpressing cells in the spleen. 

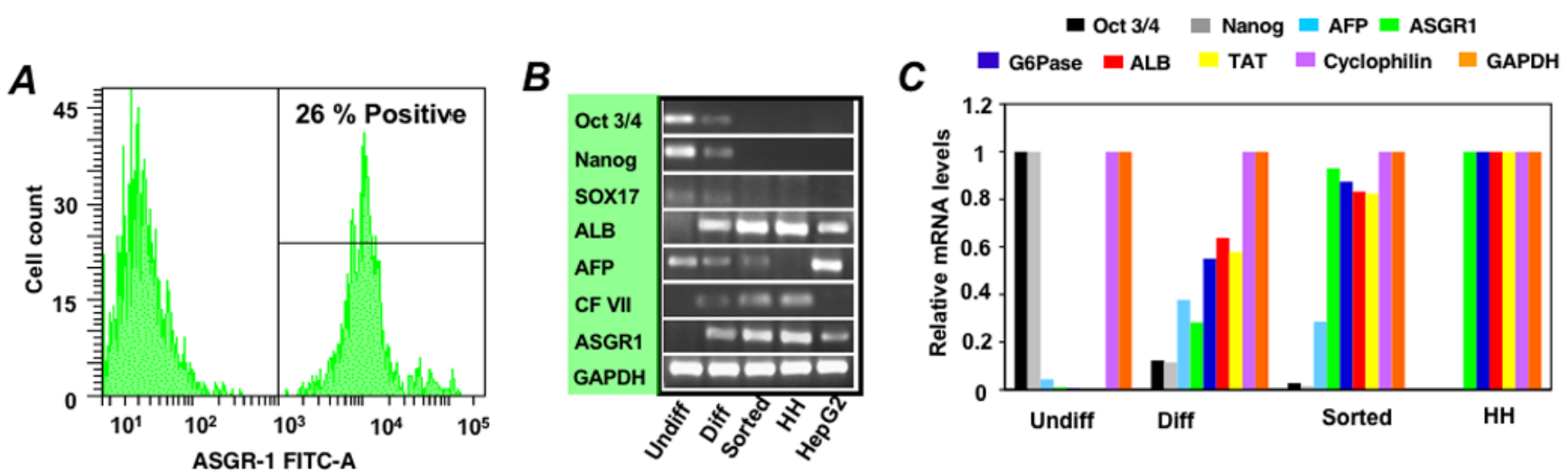

D
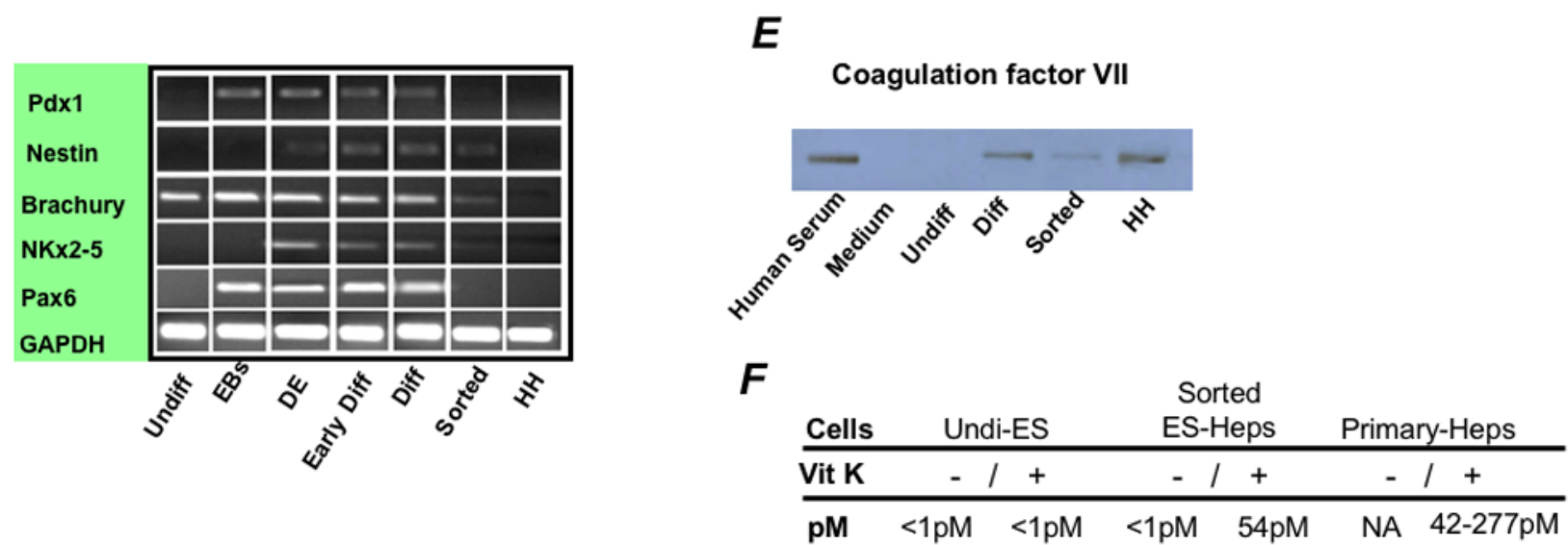

Figure 4. Enrichment of hES differentiated cells by ASGPR expression and characterization of sorted cells

(A) Flow cytometry showed that 18-26\% of differentiated cells expressed the ASGPR, a definitive feature of differentiated hepatocytes. (B) RT-PCR and (C) Real-time analysis was performed to determine gene expression levels during the various stages of differentiation and following sorting relative to levels in primary human hepatocytes (HH). Expression levels of lineage-specific hepatic markers [albumin (ALB), tyrosine aminotransferase (TAT), glucose-6-phosphatase (G6P), CF VII, and ASGPR1], endoderm (Sox17) and the gestational hepatocyte marker AFP, and markers for undifferentiated cells (Pou5f1 and Nanog) were examined and mRNA expression levels were normalized relative to GAPDH, cyclophilin, and primary human hepatocytes. (D) To assess the lineage specificity of the differentiation program, mRNA was further analyzed by RT-PCR for Pdx-1 (a pancreatic marker gene), Nestin (ectoderm), Brachury (mesendoderm), NKx2.5 (mesoderm), and Pax-6 (ectoderm).

Undifferentiated hES (lane 1), following EB formation (lane 2), hES differentiated to DE (lane 3), after culture in HGF and DMSO (early Diff; lane 4), after culture in dexamethasone (Diff; lane 5), and Diff stage cells following enrichment for ASGPR surface expression (sorted; lane 6). Primary human hepatocytes (lane 7) were used as control cells. (E) Production of CF VII protein by unsorted and ASGPR-sorted hES-derived cells was confirmed by immunoblot, and (F) functional CF VII activity in culture supernatants supplemented with Vitamin K was shown to be similar to that produced by cultured primary human hepatocytes. 

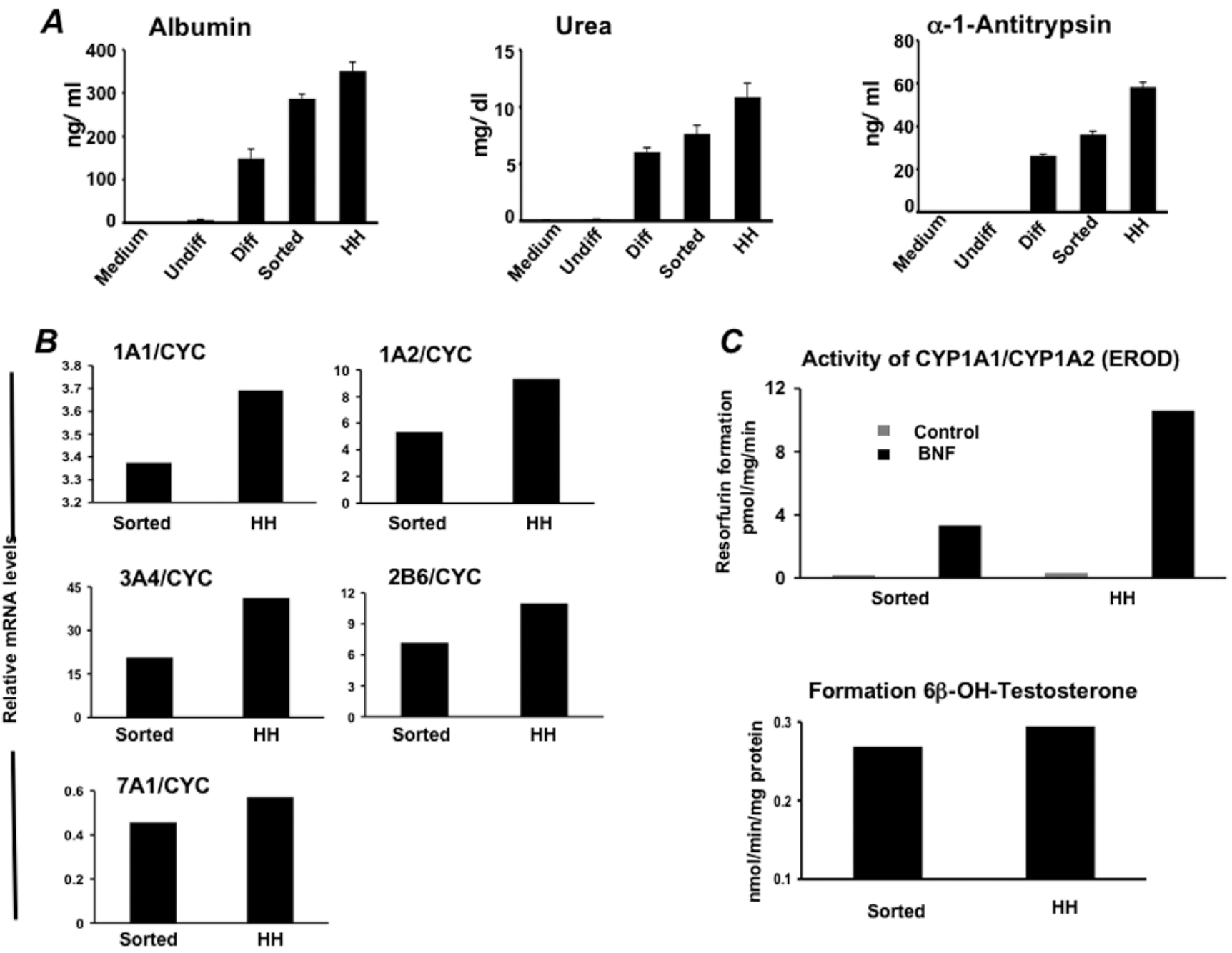

Figure 5. Functional analyses of differentiated hES cells enriched toward a hepatocyte phenotype (A) Albumin, urea, and alpha-1-antitrypsin secretion was determined in vitro by primary human hepatocytes $(\mathrm{HH})$ and hES cells during differentiation $(n=5)$. Analysis involved undifferentiated hES cells (Undiff), hES cells following EB formation (EBs), hES cells after treatment with FGF-2 and Activin-A or at the definitive endoderm (DE) stage, hES cells after culture in HGF and DMSO (early Diff), hES cells after culture in dexamethasone (Diff), and hES cells after the Diff stage and following enrichment for ASGPR surface expression. (B) Real time analysis demonstrated expression of cytochrome P450 1A1 (CYP1A1), 1A2, 3A4, 2B6, and 7A1 at levels similar to that derived from fresh primary human hepatocytes. (C) To assess human liver-specific cytochrome P450 metabolic activity, ES-derived- or normal human hepatocytes were cultured in the presence of phenobarbital or $25 \mu \mathrm{M}$ BNF. For measurement of CYP 1A activity, cells were exposed to media containing $20 \mu \mathrm{M}$ 7-ethoxyresorufin and conversion to 7-hydroxyresorufin in the media was quantified by the fluorescence of the 7hydroxy metabolite measured at $535 \mathrm{~nm}(\mathrm{Ex})$ and $581 \mathrm{~nm}(\mathrm{Em})$. Analysis of CYP3A activity was measured by conversion of testosterone to $6 \beta$-hydroxytestosterone by high pressure liquid chromatography. Studies demonstrated BNF-inducible EROD activity at approximately 25$30 \%$ of that generated by primary human hepatocytes, and baseline formation of testosterone by differentiated ASGPR-enriched cells near that produced by cultured primary human hepatocytes. 

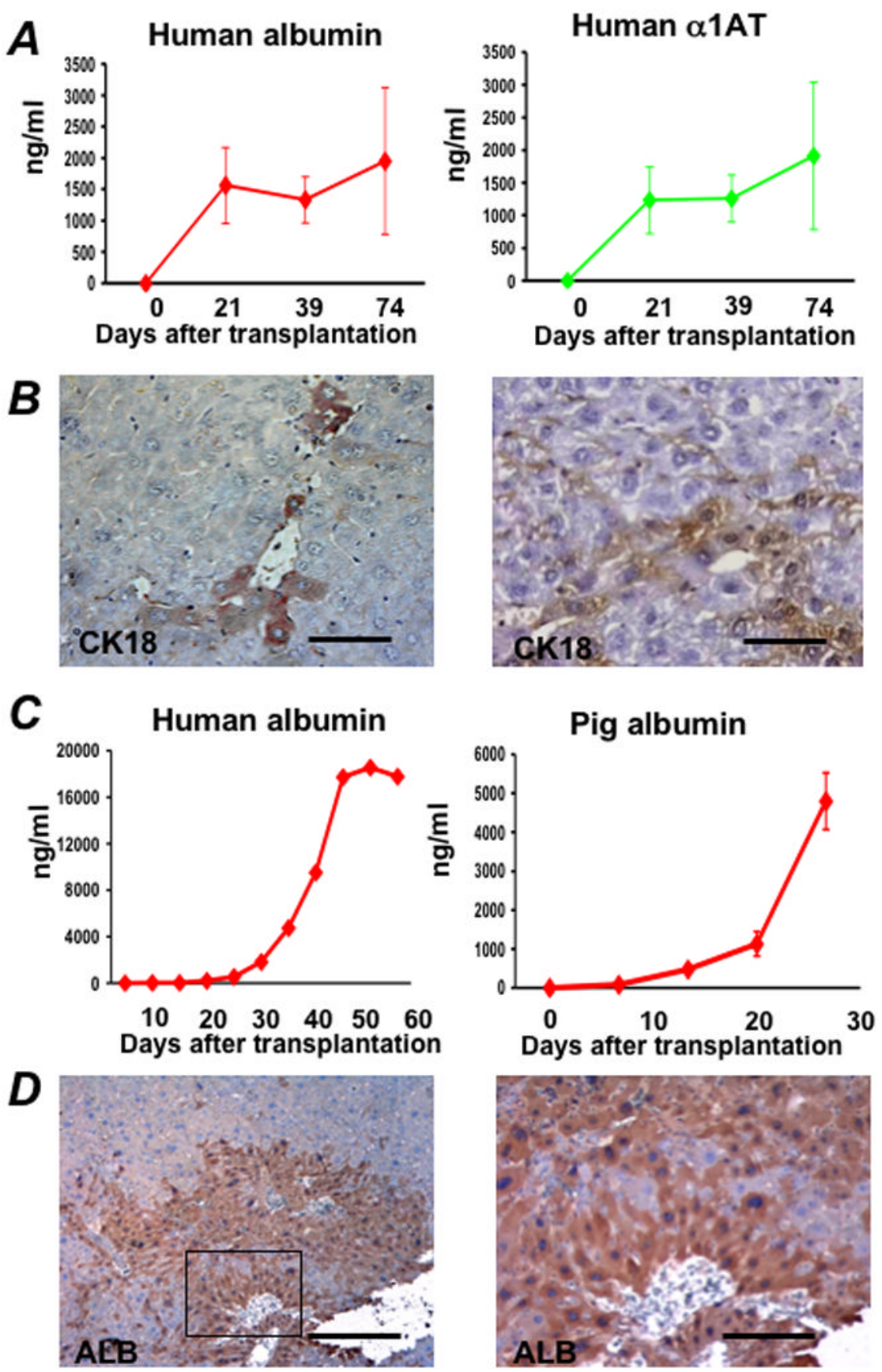

Figure 6. Transplantation of ASGPR-enriched hES-derived hepatocytes in uPA-SCID mice and an immune suppressed Nagase analbuminemic rat

One hundred thousand to two-hundred thousand hES-derived cells, sorted based on surface ASGPR expression, were transplanted in immune deficient Alb-uPA SCID mice. Following transplantation, (A) human albumin and human $\alpha 1$ AT levels were measured by ELISA. At 75 days after transplantation, the serum of these animals contained 1000-2000 ng/ml human albumin and AAT. (B) Immunohistochemistry was performed on liver sections of transplanted animals, and small clusters of human cytokeratin-18 (CK18)-staining engrafted cells, which stain dark brown, with hepatocyte morphology were present throughout the liver. (C) One million ASGPR-sorted differentiated hES cells were also transplanted into the spleen of a 
retrorsine-treated FK506 immune suppressed Nagase analbuminemic rat that underwent 70\% partial hepatectomy at the time of transplantation. Following transplantation, human albumin levels were measured at $20,000 \mathrm{ng} / \mathrm{ml}(0.2 \mathrm{mg} / \mathrm{ml})$ by ELISA 55 days after transplantation. Comparable serum porcine albumin levels were measured in control Alb-uPA SCID mice up to 28 days after transplantation with $4^{\circ} \mathrm{C} 24$-hour University of Wisconsin preserved primary pig hepatocytes. At sacrifice, immunohistochemistry demonstrated large colonies of human albumin-expressing cells (D). 